American Journal of Immunology 5 (1): 8-16, 2009

ISSN 1553-619X

(C) 2009 Science Publications

\title{
Cancer Chemotherapy and Immune Regulation
}

\author{
${ }^{1}$ John Barrett and ${ }^{2}$ Katarina Le Blanc \\ ${ }^{1}$ Hematology Branch, National Heart, Lung and Blood Institute, \\ National Institutes of Health, Bethesda, USA \\ ${ }^{2}$ Hematology Center, Division of Clinical Immunology and Transfusion Medicine, \\ Karolinska University, Hospital Huddinge, Stockholm, Sweden
}

\begin{abstract}
Problem statement: Chemotherapeutic drugs have been used to treat malignancy for over 50 years, but the potential of cytotoxic agents to suppress immunity and interfere with Immunosurveillance (IS) of cancer has been largely ignored. Assuming that the immune control of the cancer had a priori already failed, the effect was not considered to have a major impact on treatment outcome. Approach: We reviewed the literature of what is known about the effect of anti-cancer on immune function and their effects. Results: Increasing evidence suggested a role for tumor specific lymphocytes, as evidenced by the Graft-versus-Leukemia effect after allogeneic stem cell transplantation and infiltrating tumor-specific lymphocytes. A strong relationship between robust lymphocyte recovery after chemotherapy and favorable outcome, further suggested that cell mediated immunity played an important role in preventing disease recurrence after bulk reduction of the tumor by cytotoxic agents. Conclusion: We were beginning to discover mechanisms whereby cancer treatments favorably affect interactions between the immune system and the malignancy. However, at present our ability to use cancer chemotherapy to reboot the immune system in a controlled fashion was limited. Future strategies may allow us to more efficiently link cancer treatments with immune function, not only restoring but further enhancing IS by boosting T lymphocyte and Natural Killer (NK) cell recovery, increasing tumor susceptibility to T cell or NK cell attack and inducing TumorSpecific Antigen (TSA) specific T cell responded with vaccines.
\end{abstract}

Key words: Immunosurveillance, immune recovery, cancer chemotherapy

\section{INTRODUCTION}

Many chemotherapeutic agents used to treat malignant diseases damage lymphocytes and consequently suppress cell-mediated immunity. More recently, new cancer treatment agents such as tyrosine kinase inhibitors, thalidomide and its derivatives, proteasome inhibitors and interferons, have been found to have diverse immunomodulatory activities. While chemotherapy and the new biologically active agents have made a major impact on disease outcome-in particular in hematological malignancies, such treatment can affect the immune system either adversely, by blocking Immune Surveillance (IS) of the malignancy and permitting disease recurrence, or favorably, by reprogramming immunity to increase autologous anti-tumor effects. Somewhat surprisingly, interactions between cancer therapy and immunity and specifically the immune surveillance of cancer have been little explored. In this review, we summarize the evidence for IS of malignant disease in man and outline the immune mechanisms believed to be involved. We survey what is known about the impact of anti-cancer agents on immune function and immune surveillance and outline future strategies to coordinate cancer treatments with immunotherapy.

Immune surveillance of cancer: In the 1960s Thomas and Burnet proposed the idea that lymphocytes constantly seek out nascent cancers and suppress them in a process they called "Immune Surveillance" (IS) ${ }^{[1]}$. Support for cancer IS came from numerous observations of spontaneous tumor development in immunodeficient mice and in congenital and acquired $\mathrm{T}$ cell defects in $\operatorname{man}^{[2-4]}$. Today the concept of IS has broadened, with the realization that the interaction of the immune system with the malignancy is an ongoing dynamic process where immunity is modified by the

Corresponding Author: John Barrett, Hematology Branch, National Heart, Lung and Blood Institute, National Institutes of Health, Bethesda, USA 
tumor and the tumor in turn is modified by the immune system (so-called immune editing) ${ }^{[2,5]}$. The immune control of malignancy is best viewed as an equilibrium, which when perturbed, may lead to tumor escape or alternatively to tumor control and elimination. A recent study of carcinogen-induced spontaneous tumors in mice supports this model as the most likely for cancers developing in individuals with normal immune competence $^{[6]}$. When carcinogens were given to a group of susceptible mice, a proportion developed cancers. However, in $40 \%$ of mice that did not develop overt cancer, occult tumors were found which grew poorly in the presence of a competent immune system. In some animals occult tumors underwent clonal selection and then escaped to develop into lethal cancers, while others remained tumor-progression free unless immunosuppressed with cyclosporine. Immune control of the tumor could be restored with interferon gamma. These studies are important because they suggest that in man a similar equilibrium between the immune system and the cancer could be perturbed adversely by cancer treatment.

Immunosurveillance against human malignancies: While it is generally accepted that IS plays a role in the natural control of cancer occurrence and likely regulates cancer growth, evidence for IS in man is limited. Details of immune mechanisms in specific diseases are lacking and evidence is often circumstantial. Evidence supporting immune surveillance in man is listed below:

1. Tumor-infiltrating lymphocytes: Tumors with high frequencies of infiltrating lymphocytes have a more favorable prognosis (colon cancer ${ }^{[7,8]}$, ovarian cancer ${ }^{[9]}$, lymphomas $^{[10-12]}$, chronic lymphocytic leukemia ${ }^{[13]}$ ).

2. Viral tumors: Epstein-Barr Virus (EBV) and Human Papilloma Virus (HPV) tumors occur in states of $\mathrm{T}$ cell deficiency $^{[14,15]}$. EBV lymphoproliferative disease responds to adoptive $\mathrm{T}$ cell transfer and removal of immunosuppression $^{[16]}$.

Congenital immune deficiencies predisposition to lymphomas and leukemia ${ }^{[3]}$.

3. Allogeneic stem cell transplants: Allogeneic $\mathrm{T}$ cell and Natural Killer (NK) cell immune control over hematological malignancies and some solid tumors (graft-versus-leukemia and graft-versus-tumor effects) ${ }^{[17,18]}$.

4. Tumor Specific Antigens (TSA) ${ }^{[19-21]}$ : A wide spectrum of tumor-specific antigens have been described: e.g., Wilms Tumor 1 (WT1), proteinase 3 (PR1), fusion proteins products of chromosomal translocation such as BCR-ABL in chronic myeloid leukemia. T cells recognizing TSA are found widely in malignant disease with increased frequencies infiltrating the tumor or bone marrow in the case of leukemia.leukemia-antigen specific $\mathrm{T}$ cells in CML correlate with disease control $^{[22,23]}$.

5. Myelosuppressive $\mathbf{T}$ cells in Myelodysplastic Syndromes (MDS): T lymphocytes contribute to the marrow failure of some patients with MDS. About 30\% of patients with early stages of MDS respond to immunosuppression with an increase in blood counts and a loss on transfusion dependence ${ }^{[24,25]}$.

Immune suppression by anti cancer drugs: Because many anticancer chemotherapy agents cause DNA damage they can have a profound effect on proliferating lymphocytes as well as affecting generation and function of antigen-presenting cells (monocytes, macrophages, dendritic cells and B cells), derived from hematopoietic stem cells. Many cytotoxic agents have both immunosuppressive and anti tumor effects. Described below are the better-known immunosuppressive characteristics of anticancer drugs.

1. Cyclophosphamide: The alkylating agent Cyclophosphamide (Cy) was one of the first cytotoxic drugs to find a role in treating autoimmune disease. Unlike other alkylating agents $\mathrm{Cy}$ does not cause marrow stem cell failure and even in large doses it induces only a brief period of cytopenia. Cy has been widely used for prolonged periods at low doses of up to $150 \mathrm{mg}$ daily to induce lymphopenia and treat autoimmune disorders such as systemic lupus. Cy has for many years been successfully used at high doses (200 mg $\mathrm{kg}^{-1}$ ) as a single conditioning agent to immunoablate aplastic anemia recipients prior to allogeneic Stem Cell Transplantation $(\mathrm{SCT})^{[26]}$.

2. Methotrexate: Methotrexate is well established both as an anti cancer and antileukemia drug and also as an immunosuppressive agent. A cycle-active drug it can be used either in high dose single infusions or in lower repeated doses typically in autoimmune diseases. It induces apoptosis and clonal deletion of activated $\mathrm{T}$ cells $^{[27]}$.

3. Anthracyclines: This group of widely used drugs are powerfully cytotoxic to $\mathrm{T}$ cells inducing apoptosis in cycling and non-cycling cells ${ }^{[28]}$. 
4. Purine analogs: (6-mercaptopurine, thioguanine, azathioprine, cladribine, pentostatin and fludarabine) specifically target lymphoid cells which use adenosine deaminase in nuclear synthesis. While older agents (6MP and thioguanine have found a place in the treatment of Acute Lymphoblastic Leukemia (ALL) and Acute Myeloid Leukemia (AML) respectively, drugs such as azathioprine have been used more for their immunosuppressive capacity to treat autoimmune diseases. The newer agents fludarabine, pentostatin and cladribine are not only active in lymphoma treatment but have been used in stem cell transplantation for their powerful immunosuppressive properties in conditioning regimens and more recently to induce lymphopenia to improve engraftment of donor lymphocyte infusions ${ }^{[29]}$.

5. Steroids: As well as being powerful immunosuppressant's, corticosteroids are widely used in the treatment of malignancies and in particular in lymphomas. As well as being directly lympholytic, they attach to corticoid receptors on many cell types and interfere with $\mathrm{T}$ cell receptor signaling ${ }^{[30]}$.

Immunomodulation by anti cancer drugs: It is now clear that some cancer chemotherapies and newer anti cancer drugs which damage malignant cells through pathways other than by DNA damage have diverse and complicated interactions with the immune response to cancer. The main targets of these drugs are the lymphocyte subsets, Antigen-Presenting Cells (APC) and the tumor cell itself.

1. Lymphocyte cytotoxicity: Some drugs can promote immune reactivity to the tumor through promotion of the $\mathrm{T}$ helper ${ }_{1}\left(\mathrm{Th}_{1}\right)$ inflammatory cytokine producing cells (paclitaxel, cyclophosphamide) ${ }^{[31]}$, enhancing NK cell reactivity ( IMiDs ${ }^{[32]}$, bortezomib ${ }^{[33,34]}$ ), In contrast tyrosine kinase inhibitors such as imatinib and dasatinib are immunosuppressive blocking $\mathrm{T}$ cell function but sparing CD4+ CD25+ FoxP3+ regulatory $\mathrm{T}$ cells $\left(\mathrm{T}_{\text {reg }}\right)^{[35]}$.

2. Blockade of suppressor cells: Three suppressor cell types (Myeloid Derived Suppressor Cells (MDSC)), $\mathrm{T}_{\text {regs }}$ and plasmacytoid $\mathrm{DC}$ are thought to play an important role in limiting immune responsiveness to cancer ${ }^{[36]}$. Drugs which block these suppressors may be important in facilitating immune control of tumors. Gemcitabine can block MDSC ${ }^{[37]}$, IMiDs and cyclophosphamide block $\mathrm{T}_{\text {regs }}{ }^{[32]}$. During lymphocyte recovery from chemotherapy antitumor immunity is enhanced by a relatively slow recovery of $\mathrm{T}_{\text {regs }}{ }^{[38]}$ and plasmacytoid DCs ${ }^{[39]}$.
3. Tumor susceptibility to immune destruction: Drugs can render tumor cells more susceptible to immune destruction either by upregulation of target molecules to T cell and NK cell attack, or by directing cell senescence and death towards favorable pathways of antigen capture and presentation by APC. About 5 azacytidine enhances tumor antigenicity by upregulating MHC class $\mathrm{I}$ and tumor antigen expression, increasing release of proinflammatory cytokines and danger signals and promoting antigen uptake by DC and killing by NK cells ${ }^{[40]}$. Topoisomerases enhance susceptibility to NK cell cytotoxicity through upregulation of MicA/B ligands for the NK receptor $N K G 2 D^{[41]}$ mitomycin, 5fluorouracil, doxorubicin and cisplatin, increase expression of Death Receptors (DR) $4 / 5$ and Fas rendering the cell susceptible to destruction by $\mathrm{T}$ cells and NK cells expressing the corresponding ligands TRAIL and Fas ligand ${ }^{[42,43]}$.

4. APC: Many drugs such as doxorubicin and mitomycin, cyclophosphamide, vincristine and methotrexate can enhance macrophage killing ${ }^{[36]}$.

Lymphocyte recovery after high dose chemotherapy: The regeneration of $\mathrm{T}$ lymphocytes after chemotherapy is derived from two sources: The immediate $T$ cell recovery comes from expansion of post-thymic $\mathrm{T}$ cells. Later, In children and adolescents, but to a lesser extent in adults, regeneration occurs from bone marrow derived prethymic $\mathrm{T}$ cells which undergo maturation and selection in the thymus before emerging into the post-thymic compartment as naïve $\mathrm{T}$ cells. This process is slow and full recovery is constrained by chemotherapy damage to the thymic epithelium and reduced production of pre-thymic lymphocytes from the marrow ${ }^{[44,45]}$. The effect of lymphoablation is to generate a surge of lymphocyte growth factors including IL-2, IL-7 and IL-15. This so-called homeostatic drive causes rapid expansion of both $\mathrm{T}$ cells and NK cells which compete for growth factors to restore the lymphocyte count to normal levels within a few weeks. The recovering lymphocyte repertoire is distinct from a quiescent repertoire in having a preponderance of NK cells which are the first lymphocytes to recover, clonal expansion of CD8+ memory $\mathrm{T}$ cells (including tumor-specific $\mathrm{T}$ cells), especially if stimulated by the relevant antigen and a reduced frequency of $\mathrm{T}_{\mathrm{reg}}{ }^{[46,47]}$. Experience from lymphocyte-depleted stem cell transplants suggests that most NK cells are regenerated from CD34+ progenitors $^{[48]}$. These early recovering NK cells show some unusual properties: They are more immature, 
express fewer Killer Immunoglobulin-like (KIR) receptors but overexpress NKG2A. They exhibit less cytotoxicity but secrete more cytokines than mature NK cells $^{[49]}$.

Immunosuppressive effects of multiple cycles of combination chemotherapy: While individual agents clearly have immediate effects on lymphocyte counts and immune function, the widespread approach of treating both hematological and non-hematological malignancies with repeated cycles of chemotherapy given over many months has a prolonged and profound suppression of cell-mediated immunity. This is evident, for example, in the occurrence of opportunistic infection in patients treated for acute lymphoblastic leukemia and the need for continued prophylaxis against pneumocystis infection. Mackall has extensively studied immune function in patients with solid tumors receiving multiple chemotherapy cycles $^{[44,50]}$. Such treatment causes depletion of CD4 lymphocytes, which is more pronounced in adults than in children because younger individuals have more ability to restore the $\mathrm{T}$ cell repertoire through the thymus. CD8+ $\mathrm{T}$ cell numbers recover within about three months after chemotherapy but this is mainly due to an expansion of CD57+ effector CD8+ cells with a persisting depletion of the central memory pool. Bruserud et al studied immune recovery in patients with Acute Myelogenous Leukemia (AML) after chemotherapy with anthracyclines and cytosine arabinoside. The treatment caused lymphopenia, but residual $\mathrm{T}$ cells proliferated normally ${ }^{[51]}$. Specifically, CD4+ $\mathrm{T}$ cells proliferated in the presence of allogeneic stimuli and autologous leukemic blasts. Their findings suggested that the lymphopenia accompanying AML induction chemotherapy can precede accelerated lymphocyte recovery with conservation of antileukemia function ${ }^{[52]}$.

What is the evidence that cancer chemotherapy affects immune surveillance?: The most compelling evidence of the relationship between immune recovery and IS comes from an increasing number of observations that lymphocyte recovery in the first weeks after lymphopenia induced by chemotherapy or Stem Cell Transplantation (SCT) for hematological malignancies is a strong predictor of outcome, such that higher lymphocyte counts around 30 days after lymphodepleting regimens is associated with less recurrence of the original disease. A relationship between lymphocyte recovery and disease relapse was first described after allogeneic SCT where several studies in SCT from matched siblings ${ }^{[53-59]}$ and one from unrelated donors ${ }^{[60]}$ identify the lymphocyte count within one month from transplant as a powerful predictor of outcome and relapse with higher counts conferring better results. NK cells are the first lymphocytes to reconstitute after allogeneic and autologous $\mathrm{SCT}^{[49]}$ and in an analysis of lymphocyte phenotype and lymphocyte count in the first month after transplant for leukemia we found that the NK count on day 30 rather than the CD3 lymphocyte count was the strongest predictor of outcome suggesting that the degree of donor NK cell recovery was instrumental in controlling residual disease after the allograft ${ }^{[48]}$.

Accumulating data suggests that the predictive impact of lymphocyte recovery on disease relapse is not restricted to allogeneic SCT. The favorable effect on disease relapse has been described after autologous SCT for multiple myeloma ${ }^{[61,62]}$, lymphoma ${ }^{[62-64]}$ and $\mathrm{AML}^{[65]}$ and also after remission induction chemotherapy for AML and ALL ${ }^{[66,67]}$. The analysis by Behl et al is of particular interest ${ }^{[66]}$. These investigators evaluated the impact of Absolute Lymphocyte Count (ALC) on recovery in newly diagnosed AML patients treated with standard induction and consolidation chemotherapy. Superior Leukemia-Free Survival (LFS) was observed when the ALC exceeded 500 cells $\mathrm{mL}^{-1}$ at all time points between days 15-28. In patients with counts greater than 4500 cells $\mu \mathrm{L}^{-1}$ the median LFS was not reached while patients with a lower lymphocyte count had an LFS of 11 months. Multivariate analysis demonstrated ALC greater than 500 cells $\mu \mathrm{L}^{-1}$ at all time points to be an independent prognostic factor for survival. The researchers speculated that the beneficial effect on relapse was through $\mathrm{NK}$ cell recovery. The best evidence that NK cell function after chemotherapy has an impact on outcome in AML comes from work by Lowdell who measured the "Leukaemia Cytolytic Activity" (LCA) mediated by CD56+/CD3-natural killer cells of patients entering remission ${ }^{[68]}$. Disease relapse was associated with a significantly lower LCA than those who remained in remission beyond 2 years and lack of LCA in remission predicted subsequent relapse within 2 years. They concluded that NK cell function was critical to the maintenance of remission after chemotherapy for AML.

Opportunities for improving IS with chemotherapy: It is becoming clear that rather than negatively affecting immune interactions with the tumor chemotherapy-at least when used initially to reduce tumor bulk can act beneficially by rebooting the immune system, breaking tolerance to the tumor and restoring IS. 


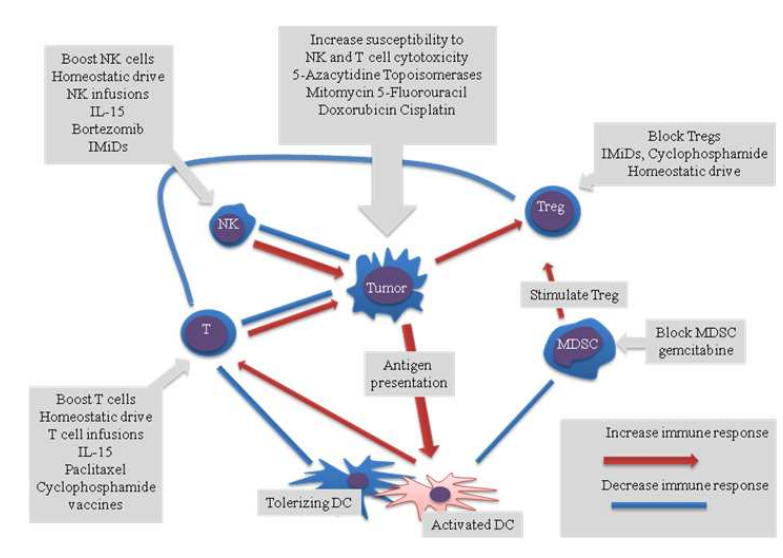

Fig. 1: Interaction of drugs with immune regulation of tumors showing potential treatment strategies. Key: MDSC: Myeloid Derived Suppressor Cell; T: T lymphocyte; NK: Natural Killer cell; DC: Dendritic Cell; Treg: CD4+, CD25+, FoxP3+ regulatory T cell. IL-15: Interleukin-15

Figure 1 outlines various approaches in use or under development. The use of anti-cancer treatments not only to treat the malignancy directly but also to exploit the immunomodulatory mechanisms is still being explored; several strategies have now been applied clinically.

The homeostatic drive: The lymphokine-driven homeostatic drive that influences both T cell and NK cell recovery has been exploited to enhance in vivo expansion of ex vivo selected tumor infiltrating lymphocytes to treat melanoma. This strategy has resulted in sustained numbers of expanded tumorspecific $T$ cells and some dramatic tumor regressions ${ }^{[46,69]}$. Alternatively the period of $\mathrm{T}$ cell expansion (in the relative absence of $\mathrm{T}_{\text {regs }}$ ) offers a unique opportunity to boost $\mathrm{T}$ cell responses to tumor vaccines ${ }^{[21,70]}$. Since the pace of lymphocyte recovery appears to be an important component of restoring IS, it would be logical to use cytokines to boost lymphocyte recovery. Although IL-2 and IL-7 have been explored, the most effective agent is likely to be IL-15 unfortunately not yet available for clinical use ${ }^{[71,72]}$.

Immunomodulation Judicious incorporation of immunomodulatory drugs described above is under active development ${ }^{[36,40]}$.

Lymphocyte infusions: The period of lymphopenia and disease bulk reduction after chemotherapy provides an opportunity for cell therapy using allogeneic NK cells which can persist short-term after fludarabinebased immunosuppressive chemotherapy. In this approach NK cells from healthy donors could be selected for their alloreactivity to the recipient cancer by KIR group mismatching and expanded in vitro prior to infusion $^{[73,74]}$. Alternatively, more speculatively, patients undergoing multiple cycles of chemotherapy could undergo lymphocyte collection and cryopreservation prior to chemotherapy in order to prevent progressive attrition of the immune repertoire by rein-fusing aliquots of autologous lymphocytes to restore immune competence after each chemotherapy cycle.

\section{CONCLUSION}

For the last 50 years cytotoxic chemotherapy has been one of the mainstays of cancer treatment. While the ability of chemotherapy treatment to induce tumor control and remission has continued to improve (notably in the hematological malignancies), chemotherapy often fails to prevent disease recurrence. It is a sobering thought that while gaining the advantage of tumor control with cytotoxic chemotherapy little thought has been given to the idea that resurrecting the immune system could reinstate effective IS. We are still exploring ways to effectively combine cancer treatment with immunotherapy. However the tools are now available to study immune recovery, modulation and function and determine the factors that produce rapid lymphocyte recovery. Such understanding should lead to realistic treatments to accelerate and enhance immune recovery, upregulate antitumor responses and transfuse $\mathrm{T}$ cells and NK cells. Beyond this is a growing ability to boost immune control both by enhancing tumor susceptibility to immune attack by innate and adaptive lymphocyte responses. Successful combination of chemotherapy with immunotherapy would appear to be the best way forward for improving the ability of chemotherapy based treatments to prevent disease recurrence and increase cure rates for many malignant diseases.

\section{REFERENCES}

1. Burnet, F.M., 1970. The concept of immunological surveillance. Prog. Exp. Tumor Res., 13: 1-27. http://www.ncbi.nlm.nih.gov/pubmed/4921480

2. Dunn, G.P., L.J. Old and R.D. Schreiber, 2004. The three Es of cancer immunoediting. Annu. Rev. Immunol., $\quad 22: \quad 329-360$. http://www.ncbi.nlm.nih.gov/pubmed/15032581

3. Filipovich, A.H., A. Mathur, D. Kamat, J.H. Kersey and R.S. Shapiro, 1994. Lymphoproliferative disorders and other tumors complicating immunodeficiencies. Immunodeficiency, 5: 91-112. http://www.ncbi.nlm.nih.gov/pubmed/8032367 
4. Swann, J.B. and M.J. Smyth, 2007. Immune surveillance of tumors. J. Clin. Invest., 117: 1137-1146. DOI: $10.1172 / \mathrm{JCI} 31405$

5. Smyth, M.J., G.P. Dunn and R.D. Schreiber, 2006. Cancer immunosurveillance and immunoediting: the roles of immunity in suppressing tumor development and shaping tumor immunogenicity. Adv. $\quad$ Immunol., 90: 1-50. http://www.ncbi.nlm.nih.gov/pubmed/16730260

6. Koebel, C.M., W. Vermi, J.B. Swann, N. Zerafa, S.J. Rodig and L.J. Old et al., 2007. Adaptive immunity maintains occult cancer in an equilibrium state. Nature, 450: 903-907. http://www.ncbi.nlm.nih.gov/pubmed/18026089

7. Galon, J., A. Costes, F. Sanchez-Cabo, A. Kirilovsky and B. Mlecnik et al., 2006. Type, density and location of immune cells within human colorectal tumors predict clinical outcome. Science, 313: 1960-1964.

http://www.ncbi.nlm.nih.gov/pubmed/17008531

8. Ohtani, H., 2007. Focus on TILs: Prognostic significance of tumor infiltrating lymphocytes in human colorectal cancer. Cancer Immunol., 7: 1-10. http://www.cancerimmunity.org/v7p10/070610.pdf

9. Sato, E., S.H. Olson, J. Ahn and B. Bundy, H. Nishikawa and F. Qian et al., 2005. Intraepithelial CD8+ tumor-infiltrating lymphocytes and a high CD8+/regulatory $\mathrm{T}$ cell ratio are associated with favorable prognosis in ovarian cancer. Proc. Natl. Acad. Sci. USA., 102: 18538-18543. http://www.pnas.org/content/102/51/18538/suppl/ DC1?ck=nck

10. Franklin, J., H. Tesch, M.L. Hansmann and V. Diehl, 1998. Lymphocyte predominant Hodgkin's disease: pathology and clinical implication. Ann. Oncol., 9: S39-S44.

http://www.ncbi.nlm.nih.gov/pubmed/9926236

11. El, W.A., S. Akhtar, W.A. Mourad, D. Ajarim and M. Abdelsalm et al., 2007. T-cell/histiocyte-rich Bcell lymphoma: Clinical presentation, management and prognostic factors: Report on 61 patients and review of literature. Leuk Lymphoma, 48: 1764-1773. http://www.ncbi.nlm.nih.gov/pubmed/17786712

12. Street, S.E., Y. Hayakawa, Y. Zhan, A.M. Lew and D. MacGregor et al., 2004. Innate immune surveillance of spontaneous B cell lymphomas by natural killer cells and gammadelta T cells. J. Exp. Med., 199: 879-884. http://www.ncbi.nlm.nih.gov/pubmed/15007091

13. Palmer, S., C.A. Hanson, C.S. Zent, L.F. Porrata and B. Laplant et al., 2008. Prognostic importance of $\mathrm{T}$ and NK-cells in a consecutive series of newly diagnosed patients with chronic lymphocytic leukaemia. Br. J. Haematol., 141: 607-614. http://www.ncbi.nlm.nih.gov/pubmed/18384436
14. Savani, B.N., S. Goodman and A.J. Barrett, 2009. Can routine posttransplant HPV vaccination prevent commonly occurring epithelial cancers after allogeneic stem cell transplantation? Clin. Cancer Res., 15: 2219-2221. http://www.ncbi.nlm.nih.gov/pubmed/19293253

15. Dolcetti, R., 2007. B lymphocytes and Epstein-Barr virus: The lesson of post-transplant lymphoproliferative disorders. Autoimmun. Rev., 7: 96-101. http://www.ncbi.nlm.nih.gov/pubmed/18035317

16. Gottschalk, S., H.E. Heslop and C.M. Rooney, 2005. Adoptive immunotherapy for EBVassociated malignancies. Leuk Lymphoma, 46: 1-10. http://www.ncbi.nlm.nih.gov/pubmed/15621775

17. Barrett, A.J., 2008. Understanding and harnessing the graft-versus-leukaemia effect. Br. J. Haematol., 142: $877-888$. http://www.ncbi.nlm.nih.gov/pubmed/18564358

18. Farag, S.S., T.A. Fehniger, L. Ruggeri, A. Velardi and M.A. Caligiuri, 2002. Natural killer cell receptors: New biology and insights into the graftversus leukemia effect. Blood, 100: 1935-1947. http://www.ncbi.nlm.nih.gov/pubmed/12200350

19. Ioannides, C.G. and T.L. Whiteside, 1993. T cell recognition of human tumors: Implications for molecular immunotherapy of cancer. Clin. Immunol. Immunopathol., 66: 91-106. http://www.ncbi.nlm.nih.gov/pubmed/8453790

20. Gannage, M., M. Abel, A.S. Michallet, S. Delluc and M. Lambert et al., 2005. Ex vivo characterization of multiepitopic tumor-specific CD8 $\mathrm{T}$ cells in patients with chronic myeloid leukemia: Implications for vaccine development and adoptive cellular immunotherapy. J. Immunol., 174: 8210-8218.

http://www.jimmunol.org/cgi/content/abstract/174/ $12 / 8210$

21. Barrett, A.J. and K. Rezvani, 2007. Translational mini-review series on vaccines: Peptide vaccines for myeloid leukaemias. Clin. Exp. Immunol., 148: 189-198. http://www.ncbi.nlm.nih.gov/pubmed/17437417

22. Molldrem, J.J., P.P. Lee, C. Wang, K. Felio and H.M. Kantarjian et al., 2000. Evidence that specific $\mathrm{T}$ lymphocytes may participate in the elimination of chronic myelogenous leukemia. Nat. Med., 6: 1018-1023.

http://www.ncbi.nlm.nih.gov/sites/entrez?Db=pubmed \& $\mathrm{Cmd}=$ ShowDetailView\&TermToSearch $=10973322$

23. Mustjoki, S., T. Lundan, S. Knuutila and K. Porkka, 2007. Appearance of bone marrow lymphocytosis predicts an optimal response to imatinib therapy in patients with chronic myeloid leukemia. Leukemia, 21: 2363-2368. http://www.ncbi.nlm.nih.gov/pubmed/17568811 
24. Sloand, E.M., C.O. Wu, P. Greenberg, N. Young and J. Barrett, 2008. Factors affecting response and survival in patients with myelodysplasia treated with immunosuppressive therapy. J. Clin. Oncol., 26: $2505-2511$. http://www.ncbi.nlm.nih.gov/pubmed/18413642

25. Barrett, A.J. and E.M. Sloand, 2009. Autoimmune mechanisms in the pathophysiology of myelodysplastic syndromes and their clinical relevance. Haematologica, 94: 449-451. http://www.ncbi.nlm.nih.gov/pubmed/19336747

26. Brodsky, R.A., 2002. High dose cyclophosphamide treatment for autoimmune disorders. ScientificWorldJournal, $\quad 2$ 1808-1815. http://www.ncbi.nlm.nih.gov/pubmed/12806171

27. Genestier, L., R. Paillot, S. Fournel, C. Ferraro, P. Miossec and J.P. Revillard, 1998. Immunosuppressive properties of methotrexate: Apoptosis and clonal deletion of activated peripheral T cells. J. Clin. Invest., 102: 322-328. http://cat.inist.fr/?aModele $=$ afficheN\&cpsidt $=10513615$

28. Ferraro, C., L. Quemeneur, A.F. Prigent, C. Taverne, J.P. Revillard and N. Bonnefoy-Berard, 2000. Anthracyclines trigger apoptosis of both G0-G1 and cycling peripheral blood lymphocytes and induce massive deletion of mature $\mathrm{T}$ and $\mathrm{B}$ cells. Cancer Res., 60: 1901-1907. http://cancerres.aacrjournals.org/cgi/content/abstra ct/60/7/1901

29. Robak, T., E. Lech-Maranda, A. Korycka and E. Robak, 2006. Purine nucleoside analogs as immunosuppressive and antineoplastic agents: Mechanism of action and clinical activity. Curr. Med. Chem., 13: 3165-3189. http://www.ncbi.nlm.nih.gov/pubmed/17168705

30. Löwenberg, M., C. Stahn, D.W. Hommes and F. Buttgereit, 2008. Novel insights into mechanisms of glucocorticoid action and the development of new glucocorticoid receptor ligands. $\quad$ Steroids, 73: 1025-1029. http://www.ncbi.nlm.nih.gov/pubmed/18221974

31. Machiels, J.P., R.T. Reilly, L.A. Emens, A.M. Ercolini and R.Y. Lei et al., 2001. Cyclophosphamide, doxorubicin and paclitaxel enhance the antitumor immune response of granulocyte/macrophagecolony stimulating factor-secreting whole-cell vaccines in HER-2/neu tolerized mice. Cancer Res., 61: 3689-3697. http://www.ncbi.nlm.nih.gov/pubmed/11325840

32. Zhu, D., L.G. Corral, Y.W. Fleming and B. Stein, 2008. Immunomodulatory drugs Revlimid (lenalidomide) and CC-4047 induce apoptosis of both hematological and solid tumor cells through NK cell activation. Cancer Immunol. Immunother., 57:1849-1859. DOI: 10.1007/s00262-008-0512-7
33. Lundqvist, A., S.I. Abrams, D.S. Schrump, G. Alvarez and D. Suffredini et al., 2006. Bortezomib and depsipeptide sensitize tumors to tumor necrosis factor-related apoptosis-inducing ligand: A novel method to potentiate natural killer cell tumor cytotoxicity. Cancer Res., 66: 7317-7325. http://cat.inist.fr/?aModele=afficheN\&cpsidt=17981442

34. Yong, A.S., K. Keyvanfar, N. Hensel, R. Eniafe and B.N. Savani et al., 2009. Primitive quiescent CD34+ cells in chronic myeloid leukemia are targeted by in vitro expanded natural killer cells, which are functionally enhanced by bortezomib. Blood, 113: 875-882. http://www.ncbi.nlm.nih.gov/pubmed/18922853

35. Seggewiss, R., D.A. Price and M.A. Purbhoo, 2008. Immunomodulatory effects of imatinib and second-generation tyrosine kinase inhibitors on $\mathrm{T}$ cells and dendritic cells: An update. Cytotherapy, 10: 633-641. DOI: 10.1080/14653240802317639

36. Ménard, C., F. Martin, L. Apetoh, F. Bouyer and F. Ghiringhelli, 2008. Cancer chemotherapy: Not only a direct cytotoxic effect, but also an adjuvant for antitumor immunity. Cancer Immunol. Immunother., $\quad$ 57: 1579-1587. http://www.ncbi.nlm.nih.gov/pubmed/18369619

37. Suzuki, E., V. Kapoor, A.S. Jassar, L.R. Kaiser and S.M. Albelda, 2005. Gemcitabine selectively eliminates splenic Gr-1+/CD11b + myeloid suppressor cells in tumor-bearing animals and enhances antitumor immune activity. Clin. Cancer Res., 11: 6713-6721. http://clincancerres.aacrjournals.org/cgi/content/ab stract/11/18/6713

38. Galustian, C., B. Meyer, M.C. Labarthe, K. Dredge and D. Klaschka et al., 2008. The anti-cancer agents lenalidomide and pomalidomide inhibit the proliferation and function of $\mathrm{T}$ regulatory cells. Cancer Immunol. Immunother., 58: 1033-1045. http://www.ncbi.nlm.nih.gov/pubmed/19009291

39. Salem, M.L., C.M. Díaz-Montero, A.A. Al-Khami and S.A. El-Naggar et al., 2009. Recovery from cyclophosphamide-induced lymphopenia results in expansion of immature dendritic cells which can mediate enhanced prime-boost vaccination antitumor responses in vivo when stimulated with the TLR3 agonist poly (I:C). J. Immunol., 182: 2030-2040.

http://www.ncbi.nlm.nih.gov/pubmed/19201856

40. Baxevanis, C.N., S.A. Perez and M. Papamichail, 2009. Combinatorial treatments including vaccines, chemotherapy and monoclonal antibodies for cancer therapy. Cancer Immunol. Immunother., 58: 317-324.

http://cat.inist.fr/?aModele $=$ afficheN\&cpsidt=21174187 
41. Gasser, S., S. Orsulic, E.J. Brown and D.H. Raulet, 2005. The DNA damage pathway regulates innate immune system ligands of the NKG2D receptor. Nature, 436: 1186-1190. DOI: 10.1038/nature03884

42. Lacour, S., A. Hammann, A. Wotawa, L. Corcos and E. Solary, 2001. Dimanche-Boitrel MT Anticancer agents sensitize tumor cells to tumor necrosis factor-related apoptosis-inducing ligandmediated caspase-8 activation and apoptosis. Cancer Res., 61: 1645-1651. http://www.ncbi.nlm.nih.gov/pubmed/11245478

43. Micheau, O., E. Solary, A. Hammann, F. Martin and M.T. Dimanche-Boitrel, 1997. Sensitization of cancer cells treated with cytotoxic drugs to fasmediated cytotoxicity. J. Natl. Cancer Inst., 89: 783-789. http://www.ncbi.nlm.nih.gov/pubmed/9182976

44. Mackall, C.L., 2000. T-cell immunodeficiency following cytotoxic antineoplastic therapy: A review. Stem Cells, 18: 10-18. http://www.ncbi.nlm.nih.gov/pubmed/10661568

45. Williams, K.M., F.T. Hakim and R.E. Gress, 2007. $\mathrm{T}$ cell immune reconstitution following lymphodepletion. Semin Immunol., 19: 318-330. http://www.ncbi.nlm.nih.gov/pubmed/18023361

46. Dudley, M.E., J.R. Wunderlich, P.F. Robbins, J.C. Yang and P. Hwu et al., 2002. Cancer regression and autoimmunity in patients after clonal repopulation with antitumor lymphocytes. Science, 298: 850-854. http://www.ncbi.nlm.nih.gov/pubmed/12242449

47. Paulos, C.M., A. Kaiser, Wrzesinski, C.S. Hinrichs and L. Cassard et al., 2007. Toll-like receptors in tumor immunotherapy. Clin. Cancer Res., 13: 52805280. DOI: 10.1158/1078-0432.CCR-07-1378

48. Savani, B.N., S. Mielke, S. Adams, M. Uribe and K. Rezvani et al., 2007. Rapid natural killer cell recovery determines outcome after T-cell depleted HLA-identical stem cell transplantation in patients with myeloid leukemias but not with acute lymphoblastic leukemia. Leukemia, 21: 2145-2152. http://www.nature.com/leu/journal/v21/n10/full/24 04892a.html

49. Storek, J., M. Geddes, F. Khan, B. Huard and C. Helg et al., 2008. Reconstitution of the immune system after hematopoietic stem cell transplantation in humans. Semin Immunopathol. 30: 425-437.

http://www.ncbi.nlm.nih.gov/pubmed/18949477

50. Mackall, C.L., T.A. Fleisher, M.R. Brown, M.P. Andrich and C.C. Chen et al., 1997. Distinctions between $\mathrm{CD} 8+$ and $\mathrm{CD} 4+\mathrm{T}$-cell regenerative pathways result in prolonged $\mathrm{T}$-cell subset imbalance after intensive chemotherapy. Blood, 89: 3700-3707. http://www.ncbi.nlm.nih.gov/pubmed/9160675
51. Bruserud, O., E. Ulvestad, S. Berentsen, J. Bergheim and I. Nesthus, 1998. T-lymphocyte functions in acute leukaemia patients with severe chemotherapy-induced cytopenia: Characterization of clonogenic T-cell proliferation. Scand J. Immunol., 47: 54-62. http://www.ncbi.nlm.nih.gov/pubmed/9467659

52. Wendelbo, Ø., I. Nesthus, M. Sjo, K. Paulsen, P. Ernst and $\varnothing$. Bruserud, 2004. Functional characterization of $\mathrm{T}$ lymphocytes derived from patients with acute myelogenous leukemia and chemotherapy-induced leukopenia. Cancer Immunol. Immunother., 53: 740-747. http://www.ncbi.nlm.nih.gov/pubmed/15133630

53. Powles, R., S. Singhal, J. Treleaven, S. Kulkarni and C. Horton, 1998. Mehta J. Identification of patients who may benefit from prophylactic immunotherapy after bone marrow transplantation for acute myeloid leukemia on the basis of lymphocyte recovery early after transplantation. Blood, 91: 3481-3486. http://www.ncbi.nlm.nih.gov/pubmed/9558408

54. Chakrabarti, S., J. Brown, M. Guttridge, D.H. Pamphilon, A. Lankester and D.I. Marks, 2003. Early lymphocyte recovery is an important determinant of outcome following allogeneic transplantation with CD34+ selected graft and limited T-cell addback. Bone Marrow Transplant., 32: 23-30.

http://www.ncbi.nlm.nih.gov/pubmed/12815474

55. Kim, D.H., J.G. Kim, S.K. Sohn, W.J. Sung and J.S. Suh et al., 2004. Clinical impact of early absolute lymphocyte count after allogeneic stem cell transplantation. Br. J. Haematol., 125: 217-224. http://www.ncbi.nlm.nih.gov/pubmed/15059145

56. Kumar, S., M.G. Chen, D.A. Gastineau, M.A. Gertz and D.J. Inwards et al., 2001. Effect of slow lymphocyte recovery and type of graft-versus-host disease prophylaxis on relapse after allogeneic bone marrow transplantation for acute myelogenous leukemia. Bone Marrow Transplant., 28: 951-956.

http://www.ncbi.nlm.nih.gov/pubmed/11753550?d opt=Abstract

57. Lee, K.H., S.J. Choi, J.H. Lee, J.S. Lee, W.K. Kim and K.B. Lee et al., 2005. Prognostic factors identifiable at the time of onset of acute graftversus-host disease after allogeneic hematopoietic cell transplantation. Haematologica, 90: 939-948. http://cat.inist.fr/?aModele=afficheN\&cpsidt $=16955657$

58. Savani, B.N., K. Rezvani, S. Mielke, A. Montero and R. Kurlander et al., 2006. Factors associated with early molecular remission after $\mathrm{T}$ celldepleted allogeneic stem cell transplantation for chronic myelogenous leukemia. Blood, 107: 1688-1695. DOI: $10.1182 /$ blood-2005-05-1897 
59. Savani, B.N., S. Mielke, K. Rezvani, A. Montero and A.S. Yong et al., 2007. Absolute lymphocyte count on day 30 is a surrogate for robust hematopoietic recovery and strongly predicts outcome after $\mathrm{T}$ cell depleted allogeneic stem cell transplantation. Biol Blood Marrow Transplant., 13: 1216-1223. http://www.ncbi.nlm.nih.gov/pubmed/17889359

60. Le Blanc, K., A.J. Barrett, M. Schaffer, H. Hägglund, P. Ljungman and M. Remberger, 2009. Lymphocyte recovery is a major determinant of outcome after matched unrelated myeloablative transplantation for myeloid malignancies. Biol. Blood Marrow Transplant., 15: 12-13. DOI: 10.1016/j.bbmt.2008.12.036

61. Hiwase, D.K., S. Hiwase, M. Bailey, G. Bollard and A.P. Schwarer, 2008. The role of stem cell mobilization regimen on lymphocyte collection yield in patients with multiple myeloma. Cytotherapy, $\quad$ 10: 507-501. http://www.ncbi.nlm.nih.gov/pubmed/18608354

62. Porrata, L.F., M.A. Gertz, D.J. Inwards and M.R. Litzow et al., 2001. Early lymphocyte recovery predicts superior survival after autologous hematopoietic stem cell transplantation in multiple myeloma or non-Hodgkin lymphoma. Blood, 98: 579-585. http://cat.inist.fr/?aModele $=$ afficheN\&cpsidt $=1052912$

63. Porrata, L.F., D.J. Inwards, S.M. Ansell, I.N. Micallef and P.B. Johnston et al., 2008. Early lymphocyte recovery predicts superior survival after autologous stem cell transplantation in non-Hodgkin lymphoma: A prospective study. Biol. Blood Marrow Transplant., 14: 807-816. DOI: 10.1016/j.bbmt.2008.04.013

64. Porrata, L.F., D.J. Inwards, I.N. Micallef, S.M. Ansell, S.M. Geyer and S.N. Markovic, 2002. Early lymphocyte recovery post-autologous haematopoietic stem cell transplantation is associated with better survival in Hodgkin's disease. Br. J. Haematol., 117: 629-633. http://www.ncbi.nlm.nih.gov/pubmed/12028034

65. Porrata, L.F., M.R. Litzow, A. Tefferi, L. Letendre, S. Kumar and S.M. Geyer et al., 2002. Early lymphocyte recovery is a predictive factor for prolonged survival after autologous hematopoietic stem cell transplantation for acute myelogenous leukemia. Leukemia, 16: 1311-1318. http://www.nature.com/leu/journal/v16/n7/full/240 2503a.html

66. Behl, D., L.F. Porrata, S.N. Markovic, L. Letendre, R.K. Pruthi and C.C. Hook et al., 2006. Absolute lymphocyte count recovery after induction chemotherapy predicts superior survival in acute myelogenous leukemia. Leukemia, 20: 29-34. http://www.ncbi.nlm.nih.gov/pubmed/16281063
67. De Angulo, G., C. Yuen, S.L. Palla, P.M. Anderson and P.A. Zweidler-McKay, 2008. Absolute lymphocyte count is a novel prognostic indicator in ALL and AML: Implications for risk stratification and future studies. Cancer, 112: 407-415. http://www.ncbi.nlm.nih.gov/pubmed/18058809

68. Lowdell, M.W., R. Craston, D. Samuel, M.E. Wood, E. O'Neill and V. Saha et al., 2002. Evidence that continued remission in patients treated for acute leukaemia is dependent upon autologous natural killer cells. Br. J. Haematol., 117: 821-827. http://www.ncbi.nlm.nih.gov/pubmed/12060116

69. Rosenberg, S.A. and M.E. Dudley, 2009. Adoptive cell therapy for the treatment of patients with metastatic melanoma. Curr. Opin. Immunol. 21:233-40.

70. Gress, R.E., K.V. Komanduri, H. Einsele and L.J. Cooper, 2007. Lymphoid reconstruction and vaccines. Biol. Blood Marrow Transplant., 13: 17-22. http://www.ncbi.nlm.nih.gov/pubmed/17222765

71. Evans, R., J.A. Fuller, G. Christianson, D.M. Krupke and A.B. Troutt, 1997. IL-15 mediates anti-tumor effects after cyclophosphamide injection of tumorbearing mice and enhances adoptive immunotherapy: The potential role of NK cell subpopulations. Cell Immunol., 179: 66-73. http://www.ncbi.nlm.nih.gov/pubmed/9259773

72. Weiss, J.M., J.J. Subleski, J.M. Wigginton and R.H. Wiltrout, 2007. Immunotherapy of cancer by IL-12-based cytokine combinations. Expert Opin. Biol. Ther., 7: 1705-1721. http://www.ncbi.nlm.nih.gov/pubmed/17961093

73. Passweg, J.R., U. Koehl, L. Uharek, S. Meyer-Monard and A. Tichelli, 2006. Natural-killer-cell-based treatment in haematopoietic stem-cell transplantation. Best Pract. Res. Clin. Haematol., 19: 811-824. http://www.ncbi.nlm.nih.gov/pubmed/16997185

74. Grzywacz, B., J.S. Miller and M.R. Verneris, 2008. Use of natural killer cells as immunotherapy for leukaemia. Best Pract. Res. Clin. Haematol., 21: 467-483.

http://www.ncbi.nlm.nih.gov/pubmed/18790450 